Article

\title{
Splenic Mass and its Relation to Age Sex and Height of the Individual in Bangladeshi Peoples
}

\author{
Khalil M ${ }^{1}$, Chowdhury MAI ${ }^{2}$, Rahman $H^{3}$, Mannan S ${ }^{4}$, Sultana SZ ${ }^{5}$, Rahman MM ${ }^{6}$, \\ Ahamed MS ${ }^{7}$, Sultana ZR ${ }^{8}$
}

The aim of this study was to establish the standard weight of the normal spleen in Bangladeshi people. One hundred and twenty human cadavers of which eighty seven male and thirty three female were dissected to remove spleen with associated structures. Collected specimens were tagged with specific identification number, and divided into five groups according to age, sex and height of the individual. Gross and fine dissections were carried out after fixing the specimen in 10\% formal saline solution.

Weight of the spleen was measured by analytical balance and expressed in gram and findings of the study were compared with the findings of national and global studies. This cross sectional descriptive study was carried out in the Department of Anatomy of Mymensingh Medical College, Mymensingh.

In this study maximum mean weight of spleen was 86.35 gram in male and 85.33 gram in female in 31 - 45 years age group. Minimum mean weight of spleen was 47.37 gram in male and 38.83 gram in female up to 15 years age group. The weight of spleen increases with age of the individual. Mean weight of spleen in male was 73.43 gram, which was higher than the mean weight of female spleen (59.17 gram). According to height of individual the mean weight of spleen was maximum 84.32 gram in 165.01 to $180 \mathrm{~cm}$ height group and minimum in 54.87 gram in up to $120 \mathrm{~cm}$ height group which indicate that weight of the spleen increases with height of the individual. In conclusion, the weight of the spleen depends on the age, sex and body height of the individual.

Key Words: Spleen, Weight, Age, Height

J Bangladesh Soc Physiol.2008 Dec;(3):71-78. For author affiliations, see end of text.

http://www.banglajol.info/index.php/JBSP

\section{Introduction}

$\mathbf{T}$ he spleen is an organ that is involved in the regulation of circulating blood volume, haematopoiesis and immunity and in the protection of the body from infections and malignancies; recently the role of the spleen in the prevention of metastasis of malignant tumour has also been emphasized ${ }^{1,2}$. Enlargement of the spleen has been of concerned to physicians as far back as ancient Greece, when it was almost certainly associated with endemic malaria.

J Bangladesh Soc Physiol. 2008 Dec;(3):71-78
The more recent observation of how often an enlarged spleen was associated with various blood diseases confirmed the relationship between the spleen and the haemopoietic system. In some of this disease the effect of splenectomy made this relationship even more apparent ${ }^{3}$. Splenic enlargement may be an important diagnostic clue to the existence of an underlying disorder ${ }^{2}$. A normal spleen weight $150 \mathrm{gm}$ and spleen weight from 400 - 500gm indicate splenomegally ${ }^{4}$. Rollo and Deland derived a formula for the in vivo estimation of liver and 
spleen masses from radionuclide images. In order to evaluate the clinical significance of splenic size, it is important to know the normal range of organ size relative to a specific parameter, e.g. body weight, height, surface area, or age ${ }^{5}$. From several studies on spleen described that, weight of the spleen decreased with ages in both sex and the spleen of female was slightly smaller ${ }^{6}$. In order to establish the normal standard of spleen weight in Bangladeshi people, 120 spleens from 200 autopsies were selected from the morgue of the Department of Forensic Medicine of Mymensingh Medical College, Mymensingh. From this study relationship of spleen size to age, sex and body height of the individual was observed.

\section{Methods}

The present study was carried out on 120 postmortem human spleens collected from Bangladeshi cadavers of both sexes (male and female) age ranging from birth to 80 years in the Department of Anatomy of Mymensingh Medical College, Mymensingh from July 2007 to June 2008.

The specimens for the study were selected from dead bodies that were under postmortem examination in the morgue of the Department of Forensic Medicine of Mymensingh Medical College, Mymensingh on different dates from October 2007 to April 2008. The spleens were chosen from individuals who died within 12 - 24 hours and discarded those were apparently ill or debilitated and the samples which were found with considerable sign of decomposition. Injured spleens, spleens of poisoning cases, known cases of diseases affecting spleen were also excluded from the present study. Since no autopsy is done for routine hospital death or other deaths from natural cause in our country, most of the spleens were collected from bodies where cause of death was medico legal i.e. road accident, suicidal, homicidal. Sufficient care was taken during removal of spleen from the cadaver to prevent undesired cutting of the tissue.
The dead bodies were kept on the table in supine position and allotted an identification number. The particulars of the body (age, sex, cause of death) were recorded in a record book against respective specimen number. Height of the cadaver was measured and recorded. After removal from the bodies the spleen were cleaned gently with running tap water. Blood and blood clots were removed as far as possible. The spleens were brought to the Department of Anatomy, Mymensingh Medical College. All fat and other unwanted associated tissue were removed from the spleen. The collected specimens were tagged by a piece of waxed cloth which bore an identifying number along with the age of victim. The collected specimen were divided into five groups- A (upto 15 years), B (16 - 30 years), C (31- 45 years), D (46 - 60 years) \& E (above 60 years) according to age and a $(0-120 \mathrm{~cm}), \mathrm{b}(120.01-135 \mathrm{~cm}), \mathrm{c}(135.01$ $-150 \mathrm{~cm}), \mathrm{d}(150.01-165 \mathrm{~cm})$ and e $(165.01-$ $180 \mathrm{~cm}$ ) group according to height for convenience of description of their various changes in relation to age, sex and height. The whole dissected specimen was placed in the fixatives ( $10 \%$ formal saline solution). The specimen was allowed to get fixed for 48-72 hours. Ignoring a little hardness and shrinkage, further study was carried out with these preserved specimens.

Weight of spleen was measured by means of a scientific balance. Before weighting, fat and unwanted tissues were removed carefully and spleen was dried with tissue paper. Weight of the spleen was expressed in gm. Collected data was noted in a tabulated form. Data were expressed as mean and $\pm \mathrm{SE}$, analysed statistically by ANOVA using computerized SPSS version-12 and findings of the present study were compared with national and international studies.

\section{Results}

Weight of 120 human spleens (Male 87 and female 33) was studied in relation to age and height of the individual. It was evident from the

J Bangladesh Soc Physiol. 2008 Dec;(3):71-78 
table I that the maximum weight of spleen in male was 132, 166, 171, 195, $79 \mathrm{gm}$ and in female was 76, 128, 107, 70, 61gm in group A, B, C, D and $\mathrm{E}$ respectively.

The minimum weight of spleen in male was 35, 47, 70, 61 and 61.50gm and in female were 20, 50, 73, 68 and $41 \mathrm{gm}$ in group A, B, C, D and E respectively. It was evident that weight of spleen was very variable with considerable overlapping between different age group.
From the figure 1 it was evident that the weight of spleen shows regular increase up to 60 years of age then weight began to decrease.

The mean $( \pm$ SE) weight of male spleen was 47.37 $\pm 14.38,86.28 \pm 6.18,88.00 \pm 4.15,86.35$ $\pm 10.12,49.35 \pm 5.02 \mathrm{gm}$ and in female was $38.83 \pm 11.01,73.83 \pm 8.91,85.33 \pm 10.86,69.00$ $\pm 1.00,49.37 \pm 1.95 \mathrm{gm}$ in group A, B, C, D and E respectively.

Difference of splenic weight between group $A$ and $\mathrm{B}, \mathrm{A}$ and $\mathrm{C}, \mathrm{A}$ and $\mathrm{D}, \mathrm{B}$ and $\mathrm{E}, \mathrm{C}$ and $\mathrm{E}, \mathrm{D}$

Table - I: Weight of Spleen in Different Age and Sex Group

\begin{tabular}{lcccc}
\hline Age group & \multicolumn{2}{c}{ Number of specimen } & \multicolumn{2}{c}{ Weight in gm (Mean \pm SE) (Range) } \\
& Male & Female & Male & Female \\
\hline A & 8 & 8 & $47.37 \pm 14.38$ & $38.83 \pm 11.01$ \\
(up to 15 years) & & & $(35.00-132.00)$ & $(20.00-76.00)$ \\
B & 26 & 12 & $86.28 \pm 6.18$ & $78.08 \pm 8.91$ \\
(16-30 years) & & & $(47.00-166.00)$ & $(50.00-128.00)$ \\
C & 29 & 3 & $88.00 \pm 4.15$ & $85.33 \pm 10.86$ \\
(31-45 years) & & & $(70.00-171.00)$ & $(73.00-107.00)$ \\
D & 13 & 2 & $86.35 \pm 10.12$ & $69.00 \pm 1.00$ \\
(46-60 years) & & & $(61.00-195.00)$ & $(68.00-70.00)$ \\
E & 11 & 8 & $49.35 \pm 5.02$ & $49.37 \pm 1.95$ \\
(Above 60 years) & & & $(40.50-79.00)$ & $(41.00-61.00)$ \\
\hline Total & 87 & 40 & $73.43 \pm 3.90$ & $59.17 \pm 5.29$ \\
& & & $35.00-195.00$ & $20.00-128.00$ \\
\hline
\end{tabular}

Significant test by- One way ANOVA

\begin{tabular}{|c|c|c|c|c|c|}
\hline \multicolumn{2}{|c|}{$\begin{array}{l}\text { Comparison between } \\
\text { different Age Groups }\end{array}$} & P value & \multicolumn{2}{|c|}{$\begin{array}{l}\text { Comparison between } \\
\text { different Age Groups }\end{array}$} & P value \\
\hline A & B & $0.000 \mathrm{HS}$ & $\mathrm{C}$ & $\mathrm{E}$ & $0.000 \mathrm{HS}$ \\
\hline A & $\mathrm{C}$ & $0.000 \mathrm{HS}$ & $\mathrm{D}$ & $\mathrm{E}$ & $0.000 \mathrm{HS}$ \\
\hline A & D & $0.000 \mathrm{HS}$ & & & \\
\hline \multicolumn{6}{|c|}{ Comparison between mean weight of male and female } \\
\hline $\begin{array}{l}\text { Sex of the } \\
\text { person }\end{array}$ & $\begin{array}{l}\text { Number of } \\
\text { the specimen }\end{array}$ & $\begin{array}{l}\text { Mean volume } \\
\text { in ml }\end{array}$ & $( \pm) \mathrm{SE}$ & T value & P value \\
\hline Male & 87 & 73.43 & 3.90 & 2.16 & $0.10 \mathrm{NS}$ \\
\hline Female & 33 & 59.17 & 5.29 & & \\
\hline
\end{tabular}

J Bangladesh Soc Physiol. 2008 Dec;(3):71-78 
Table - II: Weight of Spleen in Different Height Group

\begin{tabular}{lccc}
\hline Height group & Number of specimen & Weight in gram (Mean \pm SE) & Range \\
\hline $\mathrm{a}(0-120 \mathrm{~cm})$ & 12 & $54.87 \pm 6.23$ & $20.00-100.00$ \\
$\mathrm{~b}(120.01-135 \mathrm{~cm})$ & 11 & $58.95 \pm 6.15$ & $39.00-107.00$ \\
$\mathrm{c}(135.01-150 \mathrm{~cm})$ & 23 & $79.36 \pm 7.50$ & $32.00-171.00$ \\
$\mathrm{~d}(150.01-165 \mathrm{~cm})$ & 49 & $68.26 \pm 4.31$ & $30.00-166.00$ \\
$\mathrm{e}(165.01-180 \mathrm{~cm})$ & 25 & $84.32 \pm 6.90$ & $41.10-195.01$ \\
\hline Total & 120 & $71.54 \pm 2.91$ & $20.00-195.01$ \\
\hline
\end{tabular}

Significant test by- One Way ANOVA

\begin{tabular}{|c|c|c|c|c|c|}
\hline \multicolumn{2}{|c|}{$\begin{array}{l}\text { Comparison between } \\
\text { different height Groups }\end{array}$} & P value & \multicolumn{2}{|c|}{$\begin{array}{l}\text { Comparison between } \\
\text { different height Groups }\end{array}$} & P value \\
\hline $\mathrm{a}$ & c & $0.017 \mathrm{~S}$ & $\mathrm{~b}$ & e & $0.031 \mathrm{~S}$ \\
\hline $\mathrm{a}$ & e & $0.004 \mathrm{MS}$ & $\mathrm{d}$ & e & $0.027 \mathrm{~S}$ \\
\hline
\end{tabular}

HS Highly Significant $(\mathrm{P}<0.001)$

MS Moderately Significant $(\mathrm{P}<0.01)$

S $\quad$ Significant $(\mathrm{P}<0.05)$

NS Non Significant $(\mathrm{P}>0.05)$

and E were statistically significant. The difference was not significant between group $\mathrm{A}$ and E, B and C, B and D, C and D. The weight of male spleen was greater than the weight of female spleen but the difference was not significant.

From Table II it was evident that mean ( \pm SE) weight of the spleen in a $(0-120 \mathrm{~cm})$ height group was $54.87 \pm 6.23 \mathrm{gm}$ and the range was from 20 $-100 \mathrm{gm}$, in height group b $(120.01-135 \mathrm{~cm})$ was $58.95 \pm 6.15 \mathrm{gm}$ and range was from $39-107 \mathrm{gm}$, in c (135.01- 150cm) group mean $( \pm$ SE) weight was $79.36 \pm 7.50 \mathrm{gm}$ and range from $32-171 \mathrm{gm}$, in group $d(150.01-165 \mathrm{~cm})$ mean $( \pm S E)$ weight was $68.26 \pm 4.31 \mathrm{gm}$, range from $30-166 \mathrm{gm}$, in group e ( $165.01-180 \mathrm{~cm}) 84.32 \pm 6.90 \mathrm{gm}$ and range from 41.10 - 195gm. It was also evident that weight of spleen was very variable with considerable overlapping between different height groups. Difference of splenic weight between group a and c, a and e, b and e, d and e was significant. From the figure 2 it was evident that the weight of the spleen increases with height of the individual. There was a slight decrease in height group d due to presence of extreme age people in this height group which indicate that the weight of the spleen depends on the variation of age of people.

J Bangladesh Soc Physiol. 2008 Dec;(3):71-78 


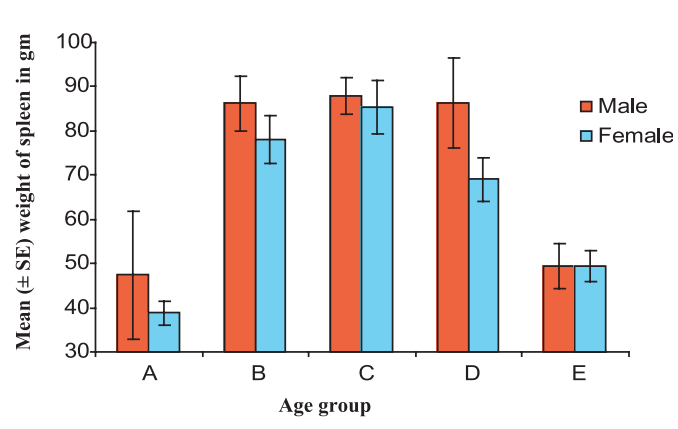

Figure 1: Bar diagram representing mean weight of spleen in different age and sex group.

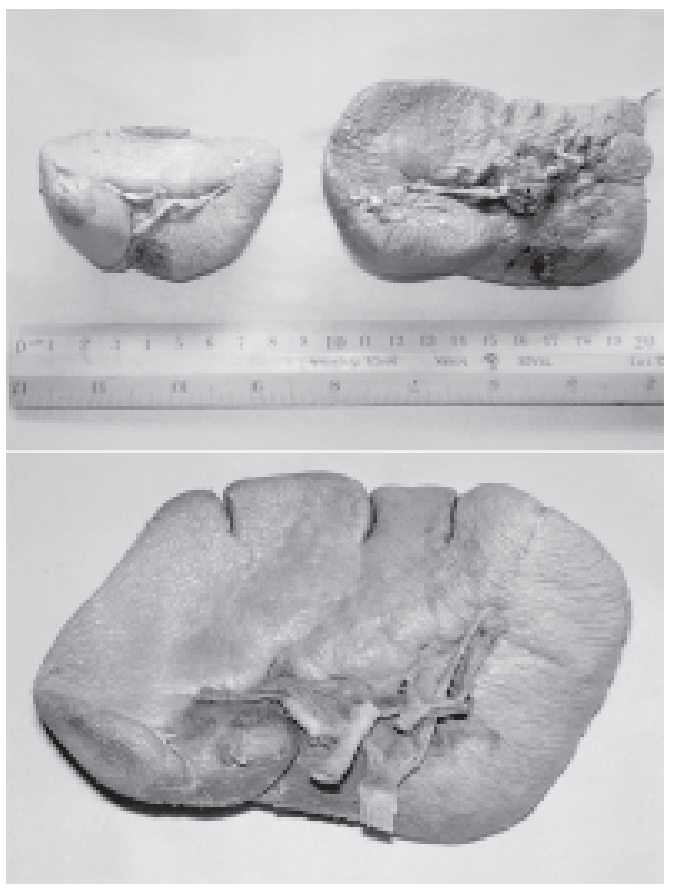

Figure 3: Spleens of different size and weight

\section{Discussion}

To establish a standard weight for normal spleen in Bangladeshi people, the present study was carried out on 120 spleens of Bangladeshi cadaver and found that, mean $( \pm \mathrm{SE})$ weight of

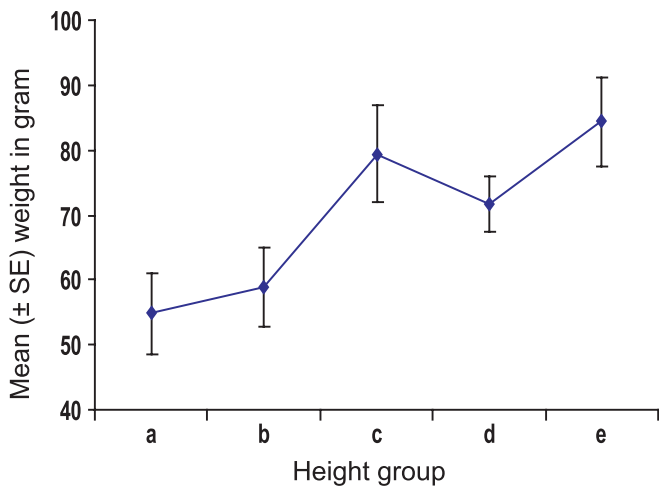

Figure 2: Line diagram representing mean weight of spleen in different height group
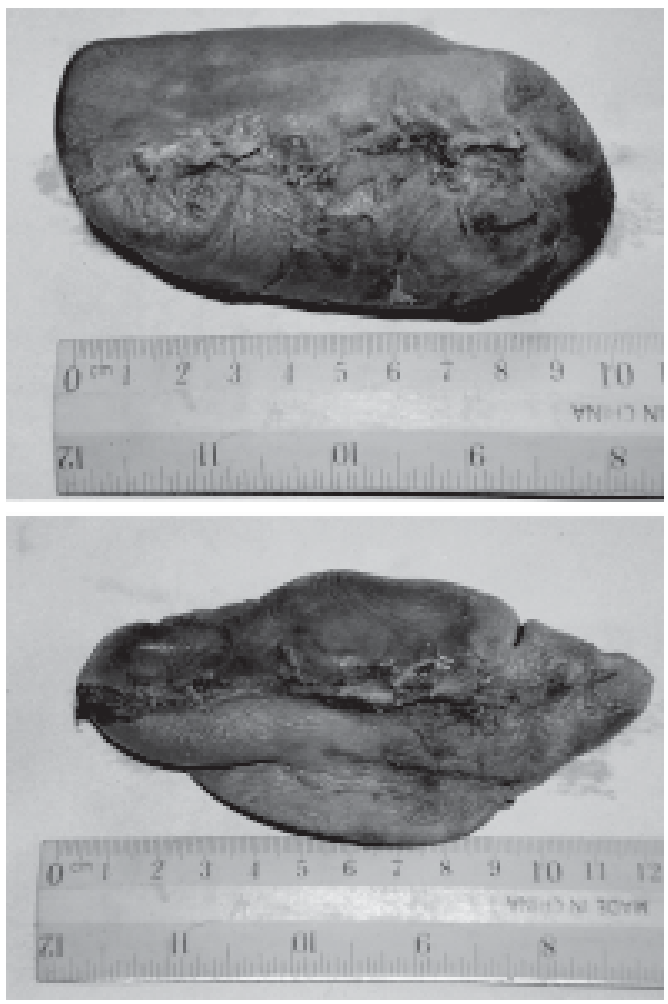

Figure 4: spleens of different size and weight

spleen was maximum in 31- 46 years age group and minimum upto 15 years age group in both male and female. The mean ( \pm SE) weight of 87 male was $73.43 \pm 5.20 \mathrm{gm}$, range from 35-195gm and of 33 female was 59.17 $\pm 5.29 \mathrm{gm}$, range from 
Article

120-128gm. Mean weight of male spleen was higher then female spleen but the deference was not significant.

It was observed in present study that, weight of spleen increases progressively with the age of the individual upto 60 years and weight of spleen was maximum in the middle age groups $(\mathrm{B}, \mathrm{C}$ and D). After 60 years, weight of spleen starts to decrease. It may be due to degeneration of tissue.

According to height of individual the mean weight was maximum $84.32 \mathrm{gm}$ in group e and minimum 54.87 gm in group a, range from 20$195 \mathrm{gm}$, which shows that the weight of spleen proportionately increases with the height of the individual.

In 2007 a study was done in Sir Salimullah Medical College under Dhaka university on spleen of 60 Bangladeshi cadaver in different age groups and described the mean $( \pm S E$ ) weight of the spleen was maximum in 40-49 years age group as $83.00 \pm 16.53 \mathrm{gm}$ and minimum 45.00 $\pm 17.73 \mathrm{gm}$ in 60 years and above age group, range from $30-120 \mathrm{gm}^{7}$. In present study the maximum mean $( \pm \mathrm{SE})$ weight of spleen was found in 31 - 45 years age group in both male and female which were close to the above mention findings. The minimum mean $( \pm \mathrm{SE})$ weight of spleen observed in upto 15 years age group in both male and female because most of the cases were close to lower limit of this age group which was not similar. Range of present study was higher than the range described by the author ${ }^{7}$.

In 2006 Rayhan studied in Dhaka Medical College under Dhaka University on 70 spleens of Bangladeshi cadavers of different age groups found that maximum mean weight of spleen was 104.64gm in 40 - 49 years age group and minimum mean weight of spleen as $61 \mathrm{gm}$ in 0 21years of age group ${ }^{8}$, which was higher than maximum and minimum mean weight of spleen of the present study in group A and C in both male and female, but the range was 30-170gm which was within the range of the present study.
Splenic Mass in Bangladesh

The mean weight of present study differs from the above mention studies ${ }^{7,8}$ because they follow DeLand for age grouping who start his grouping from 20 years and the space between the groups was 10 years ${ }^{6}$. The present study was designed to observe the changes of spleen in different age group from birth - 15 years, 16-30 years, and 31- 45 years, 46 -60 years and above 60 years age group. In present study weight was measured in relatively fresh spleen fixed after washing in running tap water to remove the remaining blood from the spleen as much as possible and clearing the related structures before measurement and most of the values in present study was close to the lower limit of their age group.

The mean weight of spleen in male and female in different age group of present study was lower than the study carried out in 1970 on 440 autopsies from 20 years to 70 years of age in Johns Hopkins Hospital and described the mean weight of male and female spleen in different age groups. At 20 - 34 years age group the mean weight of spleen was $172 \mathrm{gm}$ and $152 \mathrm{gm}$, in 35 59 years age group $169 \mathrm{gm}$ and $157 \mathrm{gm}$, in above 60 years age group 167gm and 156gm in male and female respectively ${ }^{6}$. The present study shows that the weight of spleen increases progressively with age from birth to 30 years, followed by a relative constant weight upto 60 years of age, then start to decrease above the age of 60 years which was not supported by DeLand who describe that, weight of the spleen decreases between 20 - 29 years age, followed by relative constant weight from $30-59$ years of age and start to decrease again above the age of 60 years ${ }^{6}$.

In 1933 normal variation in the weight of the spleen based upon an autopsy material was examined of which 1266 males with weight 61 $364 \mathrm{gm}$ and 316 females with weight 63 - 310gm, In 1974 study on 366 spleens was done and found that weight of spleen for male was 70 - 280 gm and female was $55-195 \mathrm{gm}^{13}$, but the authors did not mention any age group of their population. The range of splenic weight of both

J Bangladesh Soc Physiol. 2008 Dec;(3):71-78 
male and female in group C of present study was within this range.

The mean weight of spleen of group B, C and D in both male and female of present study was lower than the findings studied in 1993 on 1598 medicolegal autopsies and describe the mean weight of adult ( $>16$ years) spleen as $167 \mathrm{gm}$ for male and $117 \mathrm{gm}$ for female ${ }^{13}$.

In 1982 studied on South African people in University of CapTown, South Africa, in 2005 studied on American people in Yale University School of Medicine, Florida. The authors mentioned the mean weight of normal spleen as 150 gm, range from $80-300$ gm, which was also described by standard text books $4,9,10,11$. The authors did not mention about the age and sex of the population. If their measurement took as the normal adult value, the range of splenic weight in group $\mathrm{D}$ of both male and female of present study was within the range, but the mean weight of their study was higher than the present study.

In the present study mean weight of spleen in male was higher than the female which was supported by various studies 6,12 .

In 1965 studied carried out on 400 Caucasian and 708 Negro autopsy cases in University of Tennessee and observed that above the age of sixty years the weight of spleen starts to decrease ${ }^{12}$, which was also observed in the present study. The mean weight of spleens of the Caucasians differe significantly from the mean weight of the spleens of Negroes which indicate that weight of the spleen also influenced by races ${ }^{12}$.

In 1996 an extensive study was done on 539 autopsies of which 203 female and 336 male in the Department of Forensic Medicine in Odense University, Denmark and found that the spleen weight is positively correlated to height, body weight and degree of acute congestion but not to sex or age. They studied the weight of spleen in relation to height of the individual in different groups and observed that the weight of spleen increase with height of the individual ${ }^{13}$, which confirm the findings of present study.

J Bangladesh Soc Physiol. 2008 Dec;(3):71-78
In present study it was observed that the weight of the spleen was lower than the weight of Europeans standard because splenic weight varies in normal people with sex, age and is in proportion to body weight, height, and body surface area ${ }^{3,12,13}$ which is much higher in European people than the Bangladeshi people as, organ weight was found positively correlated to body height and body mass ${ }^{6}$. The difference may be due to racial variation, which was observed in 1965 during studying on 400 Caucasian and 708 Negro autopsy cases in University of Tennessee ${ }^{12}$.

Different authors have different inclusion criteria and the results are stated in different ways, e.g. different age grouping, mean weight or ranges, making it difficult to comparison with each other.

In this study it was observed that weight of the spleen depends on the age, sex and height of the individual which was supported by various studies. To establish a standard data on spleen in Bangladeshi people, further studies adopting better techniques on larger sample from different part of Bangladesh should be done. Factor that influence the weight of the spleen should be fixed and keep in mind.

\section{Author Affiliations}

1. * Professor Dr Mohsin Khalil, MBBS, M Phil, Professor and Head of Anatomy, MMC, Mymensingh, Bangladesh (Guide of this manuscript)

2. Professor and Head of the Department of Anatomy, MMC, Mymensingh, Bangladesh

3. Dr Md Ashraful Islam Chowdhury, M Phil, Department of Anatomy, MMC, Mymensingh, Bangladesh

4. Dr Habibur Rahman, Assistant Professor, Department of Anatomy, MMC, Mymensingh, Bangladesh

5. Dr Sabina Mannan, Assistant Professor, Department of Anatomy, MMC, Mymensingh, Bangladesh

6. Dr Seheli Zannat Sultana, Assistant Professor, Department of Anatomy, MMC, Mymensingh, Bangladesh

7. Dr Md Mahbubur Rahman, Curator, Department of Anatomy, MMC, Mymensingh, Bangladesh

8. Dr M Shibbir Ahamed, Lecturer, Department of Anatomy, MMC, Mymensingh, Bangladesh

9. Dr Zinat Rezina Sultana, Department of Anatomy, MMC, Mymensingh, Bangladesh

* For correspondence 


\section{References}

1. Liu DL, Xia S, Xu W, Ye Q, Gao Y \& Qian J. Anatomy of vasculature of 850 spleen specimens and its application in partial splenectomy . Surgery 1996 jan; 119: p. $27-33$.

2. Cortan RS, Kumar V \& Robbins SL eds. Robbins Pathologic Basis of Disease. 6th ed. New Delhi: W.B. Saunders; 2003. p. 686-90.

3. Lampert IA. 'The spleen', in Mcgee J. Isaacson PG, Wright NA, editors. Oxford text book of pathology. England: oxford university press; 1992. p. 17941807.

4. Kaplan LJ. Splenomegaly. eMedicine: 2004 octa 5;1-4.

5. Rao UVG \& Wagner HN 1972, 'Normal weight of human organs’, Radiology vol. 102, no. 337 - 9 .

6. DeLand FK 1970, 'Normal spleen size', Radiology, vol. 97, no. 2, p. 589 - 92.

7. Alim AJ. Histomorphological study and gross arterial pattern of the cadaveric spleen in Bangladeshi people [Thesis]. Dhaka: University of Dhaka; 2007.
8. Rayhan KA. Postmortem study of human spleen and splenic artery of Bangladeshi people in different age groups. M. Phil. [Thesis]. Dhaka: university of Dhaka; 2006.

9. Coetzee T. 'Clinical Anatomy and Physiology of the Spleen', South African medical journal, 1982, May15; volume 61, no 14. p. 737-46.

10. Sinnatamby CS. Last Anatomy: regional and applied. 11th ed. Edinburgh: Churchill Livingstone; 2006. p. 279-82

11. Borley NR, 'spleen', in Standring S (eds), Grays Anatomy, The Anatomical Basis of Clinical Practice, 39 th ed, London: Elsevier Churchill Livingstone;2005. p. 1437-52

12. McCormic WF \& Kashgarian M 1965, 'The weight of the adult human spleen', The American journal of clinical pathology, vol. 43, p. 332 - 3.

13. Jakobsen SS \& Jakobsen US 1997, 'The weight of the normal spleen', Forensic science international, vol. 88, p. $215-23$ 